Research Article

\title{
Distribution and biological role of the oligopeptide-binding protein (OppA) in Xanthomonas species
}

\author{
Elisa E. Oshiro ${ }^{1}$, Milene B. Tavares ${ }^{1}$, Celso F. Suzuki ${ }^{1}$, Daniel C. Pimenta ${ }^{2}$, Claudia B. Angeli ${ }^{3}$, \\ Julio C.F. de Oliveira ${ }^{4}$, Maria I.T. Ferro ${ }^{5}$, Luis C.S. Ferreira ${ }^{1}$ and Rita C.C. Ferreira ${ }^{1}$ \\ ${ }^{1}$ Departamento de Microbiologia, Universidade de São Paulo, São Paulo, SP, Brazil. \\ ${ }^{2}$ Laboratório de Biofísica e Bioquímica, Instituto Butantan, São Paulo, SP, Brazil. \\ ${ }^{3}$ Departamento de Parasitologia, Universidade de São Paulo, São Paulo, SP, Brazil. \\ ${ }^{4}$ Universidade Federal de São Paulo, Diadema, SP, Brazil. \\ ${ }^{5}$ Faculdade de Veterinária e Ciências Agrárias, \\ Universidade Estadual Paulista "Júlio de Mesquita Filho”, Jaboticabal, SP, Brazil.
}

\begin{abstract}
In this study we investigated the prevalence of the oppA gene, encoding the oligopeptide binding protein (OppA) of the major bacterial oligopeptide uptake system (Opp), in different species of the genus Xanthomonas. The oppA gene was detected in two Xanthomonas axonopodis strains among eight tested Xanthomonas species. The generation of an isogenic oppA-knockout derivative of the Xac 306 strain, showed that the OppA protein neither plays a relevant role in oligopeptide uptake nor contributes to the infectivity and multiplication of the bacterial strain in leaves of sweet orange (Citrus sinensis) and Rangpur lime (Citrus limonia). Taken together these results suggest that the $о p p A$ gene has a recent evolutionary history in the genus and does not contribute in the physiology or pathogenesis of $X$. axonopodis.
\end{abstract}

Key words: Xanthomonas, Xac, OppA, oligopeptide uptake system, ABC transporter.

Received: September 16, 2009; Accepted: December 9, 2009.

\section{Introduction}

Oligopeptides play important roles in bacterial nutrition, representing important sources of nitrogen, carbon and other elements. They are also involved in intercellular gene signaling processes, such as those involved in chemotaxis, conjugation, spore formation and the development of the competence state (Detmers et al., 2001). Three distinct oligopeptide uptake systems, specifically committed to the transport of dipeptides (Dpp), tripeptides (Tpp) and oligopeptides (Opp), have been characterized in Escherichia coli, Salmonella enterica pv Typhimurum and Sinorhizobium meliloti (Hiles et al., 1987; Nogales et al., 2009).

In gram-negative bacteria, the Opp system belonging to the ATP-binding cassette (ABC) transporter family, comprises various functional and structural domains, viz., the substrate binding protein in the periplasm (OppA), two transmembrane pore-forming proteins (OppB and OppC), and the two membrane-associated ATPases (OppD and OppF) which generate energy from ATP hydrolysis re-

Send correspondence to Rita C.C. Ferreira. Departamento de Microbiologia, Instituto de Ciências Biomédicas, Universidade de São Paulo, Av. Prof. Lineu Prestes 1374, 05508-900 Cidade Universitária, SP, Brazil. R-mail: ritacafe@usp.br. quired for the transport process. The opp genes are frequently organized as a polycistronic operon (opp $A B C D / F)$, in which the binding component (OppA) is usually expressed at a higher stoichiometric ratio compared to the other components (Higgins and Hardie, 1983; Hiles et al., 1987; Monnet, 2003). Besides a role in nutrition, the Opp system participates in various physiological processes, such as the recycling of cell-wall peptides, quorum sensing and adhesion to host cells, genetic competence and sporulation (Rudner et al., 1991; Cundell et al., 1995; Alloing et al., 1998; Claverys et al., 2000; Detmers et al., 2001). Opp-encoding genes are found in approximately $50 \%$ of those bacterial species with available genomic sequences, although as yet, in only a few cases have their specific roles, either in physiology or pathogenesis, been investigated.

The genus Xanthomonas is comprised of a ubiquitous group of bacterial pathogens which infect crops of major economical interest, such as orange, grape, rice, soy bean and bean, among others (Chan and Goodwin, 1999). Genome sequencing projects of Xanthomonas species have highlighted the multiplicity of ABC transporters, particularly those responsible for nutrient uptake (Silva et al., 
2002; Qian et al., 2005; Lee et al., 2005; Thieme et al., 2005; Salzberg et al., 2008; Vorhölter et al., 2008). So far, opp genes have been detected in the $X$. axonopodis pv. citri 306 (Vauterin et al., 1995) (Xac) strain, but not in three $X$. campestris pv. campestris $(X c c)$ strains (Silva et al., 2002; Qian et al., 2005; Vorhölter et al., 2008), neither in the genomes of X. oryzae pv. oryzae (Xoo) (Lee et al., 2005; Salzberg et al., 2008) and $X$. campestris pv. vesicatoria (Xcv) (Thieme et al., 2005). These observations indicate that the Opp system may have a specific physiological role in Xac strains and may affect features like pathogenicity and host selectivity.

In the present study, we investigated the distribution of the oppA gene among different Xanthomonas species. In addition we evaluated the putative physiological role of OppA, namely that of the oligopeptide-binding component, in the Xac 306 strain, based on the generation of a specific knockout mutant. The present evidence demonstrated that the opp $A$ gene is restricted to two $X$. axonopodis strains and does not play a specific role in the virulence of this phytopathogen.

\section{Material and Methods}

\section{Bacterial strains and growth conditions}

All the bacterial strains used in this work are listed in Table 1. Bacterial strains were routinely cultivated in Circle Grow (CG) (Bio 101) broth at $30^{\circ} \mathrm{C}$. For the oligopeptide uptake assays, the strains were cultivated overnight in M9 minimal medium supplemented with proline, methionine, histidine, tryptophan $\left(100 \mu \mathrm{g} \mathrm{mL}{ }^{-1}\right.$ each), or in the same medium with proline replaced by the YPLG peptide $(0.5 \mu \mathrm{g}$ $\left.\mathrm{mL}^{-1}\right)$.

\section{Construction of a Xac oppA-knockout strain}

The generation of an oppA-knockout Xac 306 derivative strain, denominated ХoppA2, has already been described (Oshiro et al., 2006).

\section{Gene screening and expression studies}

Genomic DNA from all the Xanthomonas isolates was isolated, according to the procedure described by Llop et al. (1999). The oppA gene was amplified with genomic DNA, as template and the oligonucleotides Fw 5'- CGGC GCTCGGGTACCGTGGCGTTGGCGGTGCTG-3' and Rv 5'- GGCGGATCTA GATCAGTGGTGGTGGTGG TGTTTGCTCACCCAGGCGTC- 3', based on the reported opp operon sequence (Silva et al., 2002). For Southern-blot analysis, genomic DNA from the tested samples was digested with Pst $\mathrm{I}$, and then transferred to a nylon membrane (Hybond-N, Amersham Biosciences). A probe for the oppA gene was synthesized with $\left[\alpha^{32} \mathrm{P}\right]-\mathrm{dCTP}$, by random primer labeling, using the PCR generated DNA fragment described above. The labeled probe was hybridized with the membrane at $42{ }^{\circ} \mathrm{C}$ for $16-20 \mathrm{~h}$ before exposure to autoradiography films (Kodak T-MAT G/RA film). Western-blot analyses were carried out with whole cell proteins sorted in $12.5 \%(\mathrm{w} / \mathrm{v})$ acrylamide gels, followed by transference to nitrocellulose membranes (Millipore) and development of bands reacting with polyclonal monospecific anti-OppA antibody, as previously described (Moutran et al., 2004). The anti-OppA serum was raised in mice

Table 1 - Bacterial strains used in the present study.

\begin{tabular}{|c|c|c|}
\hline Strains & Characteristics & Source or reference \\
\hline X. a. citri 306 & Wild type A & Silva et al., 2002 \\
\hline X. a. citri ХоррА2 & oppA::sp/sm & Oshiro et al., 2006 \\
\hline X. a. aurantifolii 409 & Wild type B & IBSBF 409 \\
\hline X. a. aurantifolii 381 & Wild type C & IBSBF 381 \\
\hline X. bromi & Wild type & LMG 947 \\
\hline X. c. campestris & Wild type & ATCC 33913 \\
\hline X. c. vesicatoria & Wild type & LMG 911 \\
\hline X. codiaei & Wild type & LMG 8678 \\
\hline$X$. melonis & Wild type & LMG 8670 \\
\hline$X . p i s i$ & Wild type & IBSBF 1356 \\
\hline X. sacchari & Wild type & LMG 739 \\
\hline X. theicolai & Wild type & LMG 8684 \\
\hline E.coli K12 SS320 & F lacI22 lacZ pro-48 met-90 trpA trpR his-85 rpsL azi-9 gyrA $\lambda^{-} P 1^{s}$ & Andrews and Short, 1985 \\
\hline E.coli K12 SS5013 & $\Delta(t d k$-oppABCDF-tonB-trp $)$ & Andrews and Short, 1985 \\
\hline
\end{tabular}

ATCC - American Type Culture Collection.

IBSBF - Biological Institute Culture Collection of Phytopathogenic Bacteria.

BCCM-LMG - Belgian Co-ordinated Collections of Microorganism-Laboratorium voor Microbiologie. 
parenterally immunized with a His-tagged protein produced in E. coli transformed with a recombinant pET-28a vector carrying the Xac орpA gene without the native signal peptide (Moutran et al., 2004).

\section{Oligopeptide uptake assay}

Xас 306 and XоррА2 cells, grown overnight, were harvested by centrifugation, washed twice with saline and inoculated (1:100) in the M9 medium without proline and with the tetrapeptide YPLG (Sigma) $\left(0.5 \mu \mathrm{g} \mathrm{mL}^{-1}\right)$. After various incubation periods at $28{ }^{\circ} \mathrm{C}$, aliquots of the culture supernatant were harvested and dried by vacuum centrifugation. The peptides were extracted with cold methanol and submitted to RP-HPLC separation (LC 10A-VP binary Shimadzu HPLC system). Each fraction was analyzed in an ESI mass spectrometer (LCQDuo, ThermoFinnigan, USA), equipped with a nanospray source and connected to a nanoHPLC system (UltiMate HPLC System, LC Packings, Dionex, USA). The samples were introduced into the spectrometer by a flow rate at $1 \mu \mathrm{L} / \mathrm{min}$, and then diluted in a solution of $5 \%$ acetonitrile and $0.2 \%$ formic acid. The spray voltage was kept at $1.8 \mathrm{kV}$, capillary voltage at $46 \mathrm{~V}$, capillary temperature at $180{ }^{\circ} \mathrm{C}$ and tube lens offset at $-5 \mathrm{~V}$. MS spectra were collected in centroid mode in the 50 to $2000 \mathrm{~m} / \mathrm{z}$ range.

\section{Protease assays}

Cell-free culture medium aliquots of Xac 306 and ХоррА 2 strains prepared in M9 medium, were incubated with YPLG $\left(0.5 \mu \mathrm{g} \mathrm{mL}^{-1}\right)$ for different periods at $20-28^{\circ} \mathrm{C}$. The presence of the tetrapeptide was monitored by RPHPLC fractionation, and the samples analyzed by mass spectrometry, as described above. The same experiments were repeated in the presence of EDTA (ethylenediaminetetraacetic acid) added to the medium aliquots at a final concentration of $1 \mathrm{mM}$.

\section{Plant infection experiments}

Cells of the Xac 306 and XoppA2 strains were diluted in sterile destilled water to a final absorbance $\left(\mathrm{OD}_{600}\right)$ of 0.3 . Aliquots $(100 \mu \mathrm{L})$ of cell suspensions were inoculated into the leaves of two sensitive citrus hosts, namely sweet orange (Citrus sinensis) and Rangpur lime (Citrus limonia), through injuries in the leaf surface. Infiltrations were carried out at the lower part of the leaf using a needleless syringe, as previously reported by Laia et al. (2009).

\section{Studies of in vivo growth kinetics}

In vivo growth tests of $X a c$ strains were carried out with sweet orange (C. sinensis). The whole procedure followed the experimental conditions described by Laia et al. (2009). Five discs of at least 6 different leaves were assayed for each time point and for each tested bacterial strain.

\section{Results}

Opp genes have only been discovered in the genome of the Xac 306 strain (Silva et al., 2002). Moreover, no orthologs have been detected in genomes of the Xcc ATCC33913, 8004 and B100 strains (Silva et al., 2002; Qian et al., 2005; Vorhölter et al., 2008), the Xcv 85-10 strain (Thieme et al., 2005), nor the Xoo strains KACC10331 (Lee et al., 2005), PX099A (Salzberg et al., 2008) and MAF311018 (GenBank accession number AP008229). These results indicate that opp genes are restricted to Xac and may have a specific physiological role, such as host specificity, in this bacterial species. To further investigate the distribution of the Opp system in Xanthomonas species, the oppA gene was screened in eight additional Xanthomonas species without known genome sequences, including one additional $X c v$ strain, six isolates of different Xanthomonas species (X. bromi, X. codiaei, X. sacchari, X. pisi, X. theicola, and X. melonis, and two $X$. axonopodis pv aurantifolii (Xaa) strains (409 and 381). As shown in Figure 1, the opp $A$ gene was detected only in the Xac 306 and Xaa 381 strains, previously classified within the citrus pathovar, but currently, and according to the low DNA homology with $X a c$ strains, considered as belonging to a different pathovar altogether (Schaad et al., 2005). The oppA gene detected in both strains were actively transcribed and translated during in vitro growth. This was demonstrated by Western-blot analysis carried out with a specific anti-OppA polyclonal antibody generated in mice immunized with purified recombinant OppA protein from the Xac 306 strain. As shown in Figure 1C, the anti-OppA serum recognized a reactive protein band in the periplasm fraction of the two X. axonopodis strains (Xac 306 and Xaa 381 ), but not in extracts of any other Xanthomonas species

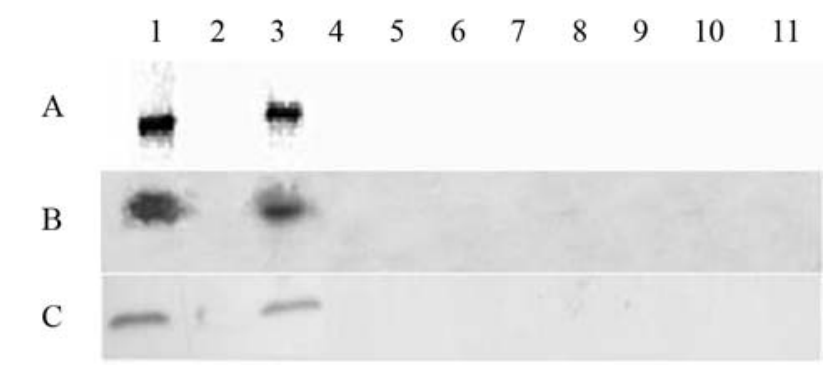

Figure 1 - Detection of oppA gene and encoded protein (OppA) among different Xanthomonas species or strains. (A) The oppA gene was detected by PCR amplification with primers annealing with the genome sequence reported for the Xac 306 strain. Samples: 1, Xac 306 strain; 2, Xaa 409 strain; 3, Xaa 381 strain; 4, Xcc ATCC33913; 5, X. bromi LMG947; 6, X. codiaei LMG8678; 7, X. sacchari LMG739; 8, Xcv LMG911; 9, X. pisi IBSBF1356; 10, X. theicolai LMG8684; 11, X. melonis LMG8670. (B) Detection of the oppA gene by Southern blotting with a probe generated with the oppA gene of the Xac 306 strain. Sample order according to the distribution in panel (A). (C) Detection of the OppA protein in immuno blots, carried out with anti-OppA serum and periplasmic proteins of Xanthomonas species and strains. Sample order according to the distribution in panel (A). 
or strain. The expression of OppA protein was apparently constitutive, since no significant difference in its expression was detected in whole-cell extracts of cells kept under different culture medium conditions, supplemented or not with oligopeptides or leaf extracts of susceptible citrus hosts (data not shown).

The restricted distribution of the oppA gene in the Xanthomonas genus suggests that the Opp system plays a specific physiological role in these two strains, but not in the other tested species and strains. In order to investigate the putative role of OppA in the uptake of oligopeptides by $X$. axonopodis strains, we generated an isogenic opp $A$ defective knockout mutant strain (Xopp $A 2)$ by a gene replacement approach in which the native gene was replaced by non-functional knockout alleles.

A

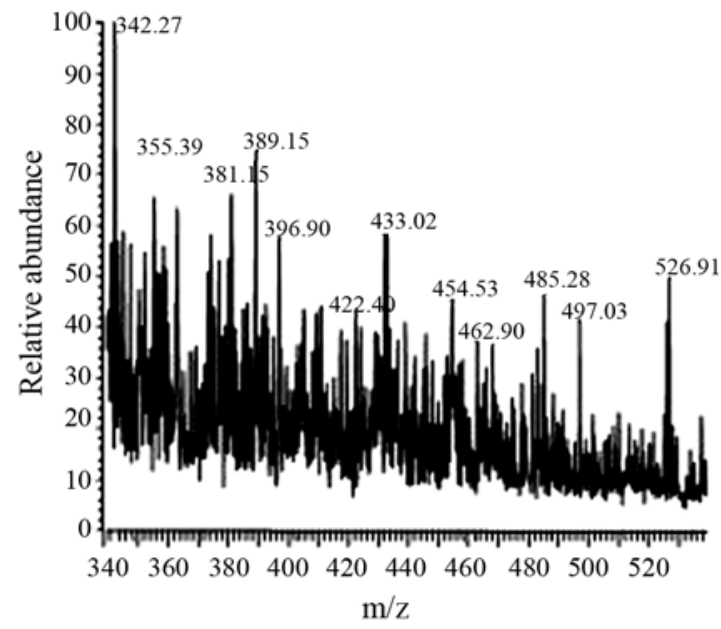

$\mathrm{C}$

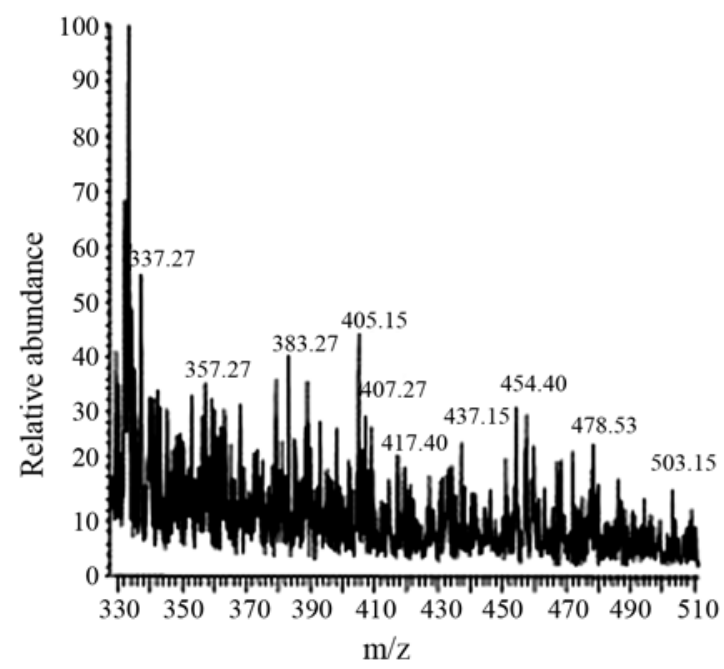

The uptake of a synthetic tetrapeptide (YPLG) was monitored by mass spectrometry, using both the parental Xac 306 strain and the OppA-deficient XоррA2 strain based on the removal of the synthetic peptide from the culture medium during bacterial cell growth. The choice of the substrate peptide was based mainly on molecular modeling studies and docking analyses of different peptides to the Xac OppA structural model (Moutran et al., 2007). In order to validate the experimental approach, we employed two $E$. coli strains: one (the SS320 strain) proficient in the opp operon, and the other (the SS5013 strain) being an isogenic derivative deleted in the entire opp operon (Andrews and Short, 1985). As indicated in Figures 2A and 2B, the oligopeptides were efficiently removed from the culture supernatant by the E.coli SS320 strain, but not by the opp-defi-

B

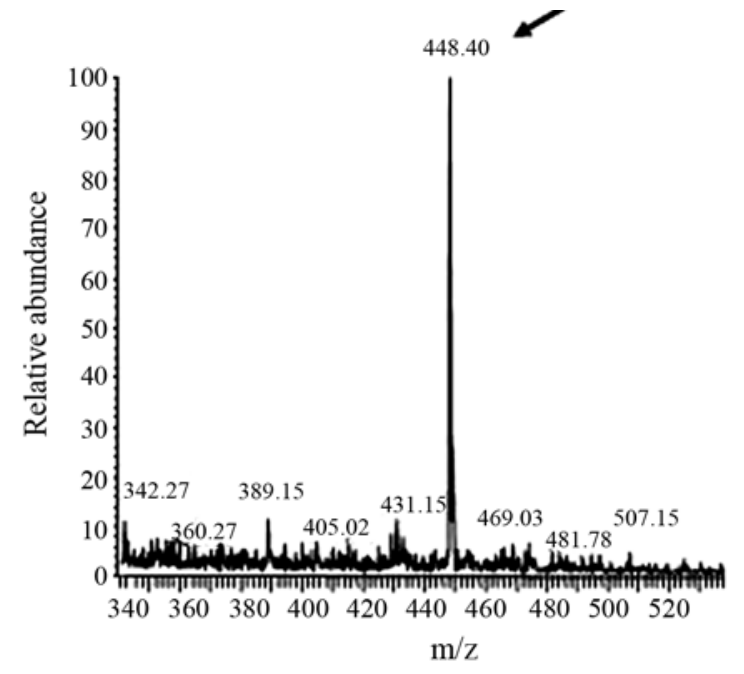

D

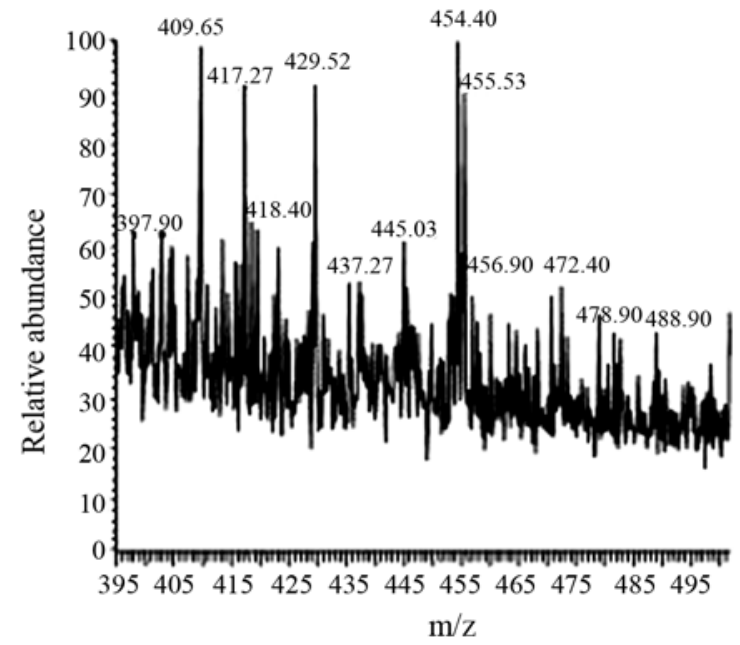

Figure 2 - Oligopeptide uptake by E. coli K12 and Xac 306 strains. The profiles show the relative abundance versus mass spectrum (m/z=448.4) corresponding to YLPG. (A) Profile detected in culture supernatant of $E$. coli SS320 strain in which no signal can be detected at $\mathrm{m} / \mathrm{z}=448.4\left(\mathrm{range} 2 \times 10^{3}\right.$ ). (B) Peptide profile detected in culture supernants of E. coli SS5013 (opp defective) strain, in which the presence of the tetrapeptide is clearly visible, as indicated by the arrow (range $2 \times 10^{5}$ ). (C) Culture supernatant of the Xac 306 strain, in which no matching ion corresponding to YLPG could be detected (range $5 \times 10^{3}$ ). (D) Culture supernatant of the XoppA2 strain, in which no matching ion corresponding to YLPG could be detected (range $8 \times 10^{2}$ ). The arrow points to the ion corresponding to the YLPG peptide. 
cient SS5013 strain. On the other hand, when the same experiment was repeated with Xac 306 and its isogenic $о р p A^{-}$derivative, ХорpA2, no tetrapeptide was detected in the culture supernatants of either strain, after incubation periods ranging from 12 to $24 \mathrm{~h}$ at $28^{\circ} \mathrm{C}$ (Figure 2C,D). This might be explained, either by the presence of an alternative Opp-independent oligopeptide uptake system in the Xac 306 strain, or by the production and secretion of proteases in the culture media.

In order to discover the reason for the rapid removal of tetrapeptide from $\mathrm{Xac}$ cultures, the oligopeptide was incubated with aliquots from the culture supernatant of both $X a c$ strains. No tetrapeptide was detected after incubation with culture supernatants of both parent and mutant strains (Figure 3B/D). In addition, EDTA prevented the in vitro
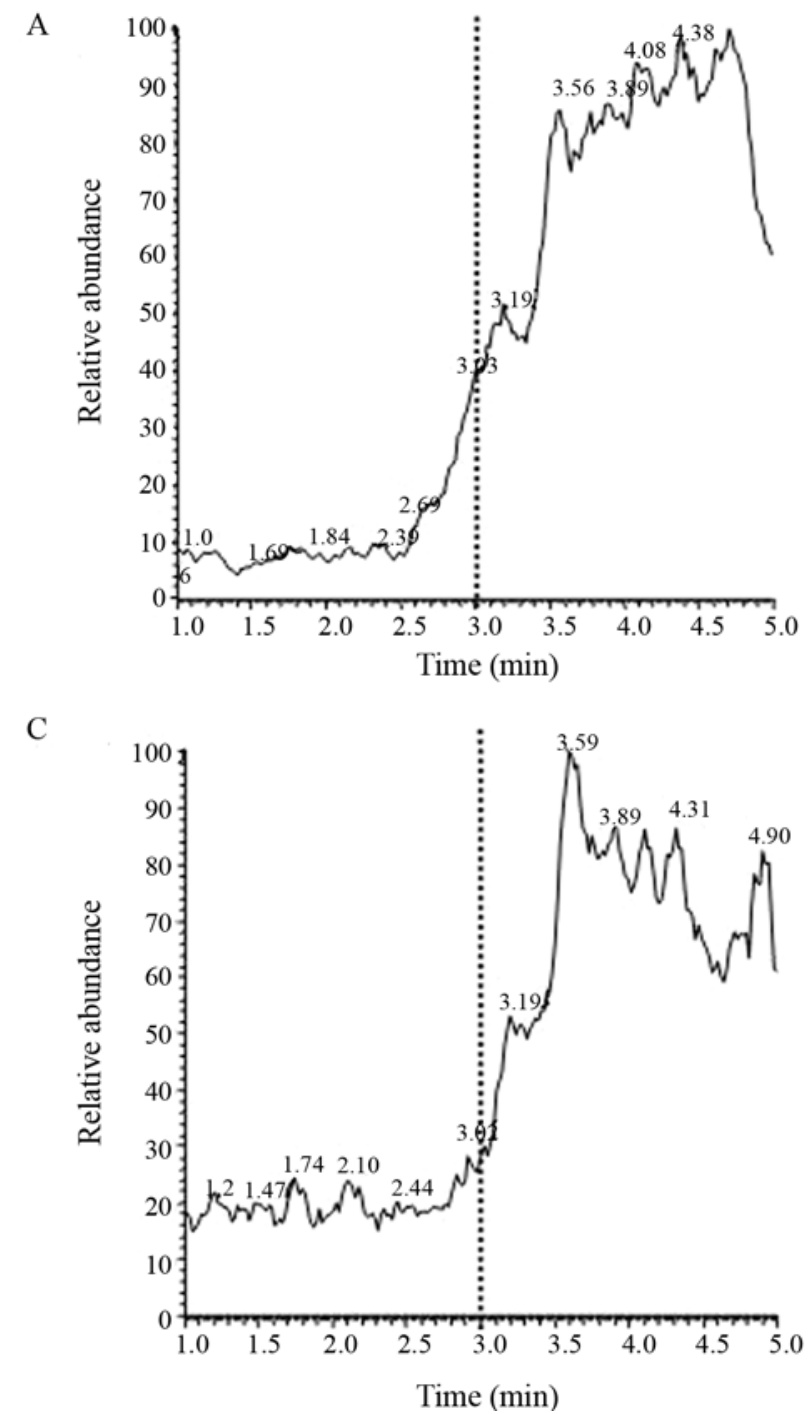

peptide degradation following incubation with culture supernatants of both Xac strains (Figure 3A,C). Such result indicated that the apparent uptake of the tetrapeptide was mainly attributed to the proteolytic attack by secreted proteases produced by the Xac 306 strain. Attempts to block protease activity in culture supernatants of actively growing Xac strains with EDTA failed, probably due to the large amount of secreted proteases (data not shown).

In order to evaluate the putative role of OppA in Xac pathogenesis in citrus hosts, we infected two susceptible citrus hosts, viz., sweet orange (C. sinensis) and Rangpur lime (C. limonia), with the Xac 306 and XoppA2 strains, and compared the induction of leaf lesions and multiplication in leaf tissues. Up to 10 days following infection, no difference was detected in the symptoms inflicted by the

B

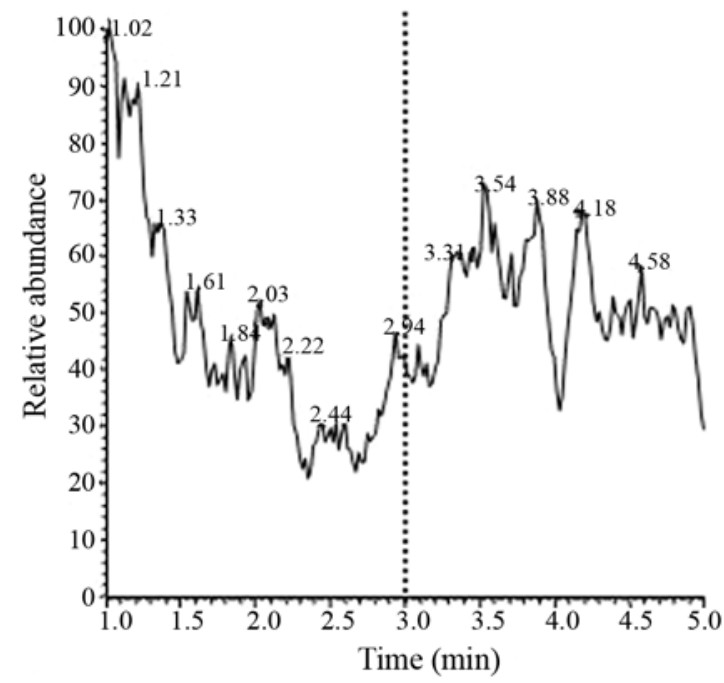

$\mathrm{D}$

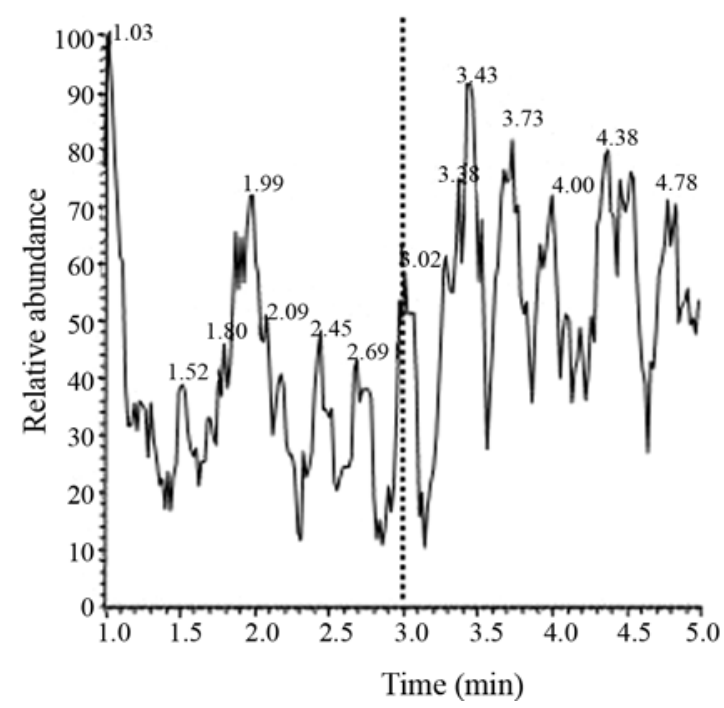

Figure 3 - Proteolytic degradation of the tetrapeptide in culture supernatants of Xac 306 and XoppA2 strains. The profiles show relative abundance versus time, with the YLPG peptide elutin after 3 min. Profiles detected in culture supernatant of the Xac 306 strain (A) with EDTA (range of $\left.2.6 \times 10^{4}\right)$ or (B) without EDTA (range of $1.2 \times 10^{5}$ ). Profiles detected in culture supernatant of the XoppA2 strain (C) with EDTA (range of $\left.7.6 \times 10^{3}\right)$ or (D) without EDTA (range of $1.5 \times 10^{5}$ ). In both samples treated with EDTA, the absorbance peak corresponding to the YLPG peptide is clearly present. The dotted line indicates the 3 min elution time. 
two Xac strains in either citrus host (Figure 4). Furthermore, no significant difference in the growth curves of either of the two strains was detected during their multiplication in sweet orange leaf tissues (Figure 4). These results clearly indicated that deletion of the $о p p A$ gene did not impair the growth of Xac in susceptible citrus hosts.

\section{Discussion}

In the present study we investigated the prevalence of the oppA gene, and the corresponding OppA protein, in different Xanthomonas species, an important group of phytopathogens inflicting heavy losses in several economically relevant crops. The present results demonstrated that, in contrast to other bacterial groups, such as enterobacterial species and lactic acid bacteria, the opp $A$ gene was detected in only two out of the three tested $X$. axonopodis strains. Furthermore, studies screening revealed that opp $A$ is also absent in the genomes of the Xccs 8004 and Xcv 85-10 strains, as well as two Xoo strains with reported genome sequences (Lee et al., 2005; Thieme et al., 2005). We also demonstrated that early-branching Xanthomonas species, including the ancestral $X$. sacchari and $X$. theicola, do not carry the $о р p A$ gene. Similarly, as recently defined by Parkinson and colleagues (2007), other three established Xanthomonas phylogenetic groups, represented by $X$. bromi, $X$. melonis, $X$. pisi and $X$. codiaei, also do not carry the opp $A$ gene. In spite of our previous observations that the
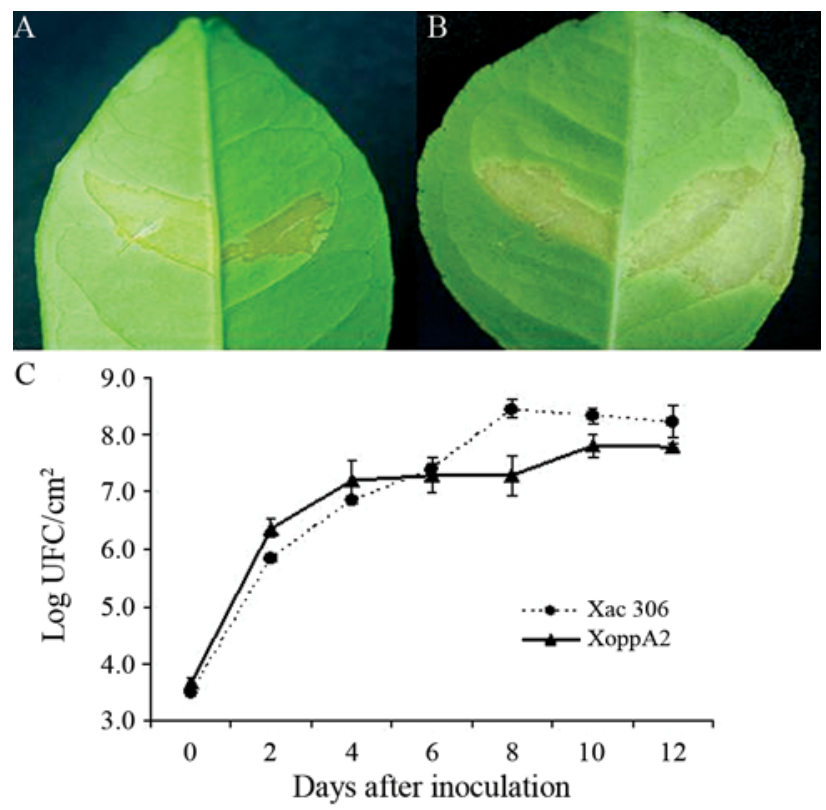

Figure 4 - Growth of Xac 306 strain and the isogenic oppA knockout mutant in susceptible citrus hosts. Leaf lesions caused in (A) sweet oranges $(C$. sinensis) and (B) Rangpur lime (C. limonia) after infection with the Xac 306 strain (left side) or XoppA2 strain (right side). Both strains were applied on the abaxial surface of the leaves and photographed 10 days after inoculation. (C) Growth kinetics of the Xac 306 and XoppA2 strains after inoculation in sweet orange leaves. Growth of the Xac $306(\bullet)$ and XoppA2 strains ( $\mathbf{A}$ ) was followed during a period of 12 days. opp operon does not present biased codon usage, distinct $\mathrm{GC}$ content or the presence of adjacent insertion sequences and transposase-encoding genes (Moutran et al., 2004), the present results indicate that the opp genes have been acquired in a recent evolutionary event in the Xanthomonas genus and remained restricted to some $X$. axonopodis strains.

Generation of an oppA-deficient strain led us to conclude that the Opp system does not play a significant role in the uptake of a tetrapeptide, the most likely substrate of OppA encoded by the Xac 306 strain, as previously determined by molecular modeling tools (Moutran et al., 2007). Monitoring of the peptide uptake by mass spectrometry showed that, in contrast to $E$. coli, the tetrapeptide is quickly degraded by secreted proteases produced by both Xac 306 and XoppA2 strains. Hence, it may be deduced that the abundant production of extracellular proteases produced by Xac, as well as other Xanthomonas species, could constitute an abundant source of amino acids derived from the proteolytic degradation of host proteins. Under such conditions, the function of an oligopeptide uptake system would be dispensable, since free amino acid residues are actively transported by different dedicated uptake systems. This conclusion is supported by the lack of the opp $A$ gene in most Xanthomonas species and the presence of a stop codon located 129 bp downstream of the first structural codon in the Xac $306 \mathrm{oppD} / \mathrm{F}$ cistron, this encoding the ATPase component required for the generation of energy to the transport process (Silva et al., 2002; Moutran et al., 2004). The finding that eight other Xanthomonas species, besides one Xaa strain, which do not carry opp genes, lends further support to the notion that, in contrast to other bacterial species, Xanthomonas oppA genes really represent pseudo genes on the way to disappearing from the genomes of these strains.

In accordance with this idea, no measurable difference in colonization, infection and generation of leaf lesions was observed in two susceptible citrus hosts infected with either the Xac 306 or the isogenic oppA-deficient strains. The absence of any significant pathogenic impact involving the Xac 306 strain in various citric hosts, lends further support to the conception that the Opp system is not functional in this strain and does not contribute to the pathogenesis of this bacterial strain in different citrus hosts. Collectively, the present evidence indicates that the Xac OppA, and consequently the Opp system, in contrast to other bacterial species, does not play a relevant physiological role.

\section{Acknowledgments}

The present study was supported by a grant from the Fundação de Amparo à Pesquisa do Estado de São Paulo (FAPESP). The authors would like to thank the helpful 
technical assistance of Loren C. Silva, Cristiano B. Ferreira, and Marcelo Laia. We wish to especially thank Dr. Y.B. Rosato for supplying us with most of the tested Xanthomonas strains.

\section{References}

Alloing G, Martin B, Granadel C and Claverys JP (1998) Development of competence in Streptococcus pneumonaie: Pheromone autoinduction and control of quorum sensing by the oligopeptide permease. Mol Microbiol 29:75-83.

Andrews JC and Short SA (1985) Genetic analysis of Escherichia coli oligopeptide transport mutants. J Bacteriol 161:484-492.

Chan JW and Goodwin PH (1999) The molecular genetics of virulence of Xanthomonas campestris. Biotechnol Adv 17:489508.

Claverys JP, Grossiord B and Alloing G (2000) Is the AmiAliA/B oligopeptide permease of Streptococcus pneumoniae involved in sensing environmental conditions? Res Microbiol 151:457-63.

Cundell DR, Pearce BJ, Sandros J, Naughton AM and Masure HR (1995) Peptide permeases from Streptococcus pneumoniae affect adherence to eucaryotic cells. Infect Immun 63:2493-2498.

Detmers FJ, Lanfermeijer FC and Poolman B (2001) Peptides and ATP binding cassette peptide transporters. Res Microbiol 152:245-258.

Higgins CF and Hardie MM (1983) Periplasmic protein associated with the oligopeptide permeases of Salmonella typhimurium and Escherichia coli. J Bacteriol 155:14341438.

Hiles ID, Gallagher MP, Jamieson DJ and Higgins CF (1987) Molecular characterization of the oligopeptide permease of Salmonella typhimurium. J Mol Biol 195:125-142.

Laia ML, Moreira LM, Dezajacomo J, Brigati JB, Ferreira CB, Ferro MI, Silva AC, Ferro JA and Oliveira JC (2009) New genes of Xanthomonas citri subsp. citri involved in pathogenesis and adaptation revealed by a transposon-based mutant library. BMC Microbiol 16:9-12.

Lee BM, Park YJ, Park DS, Kang HW, Kim JG, Song ES, Park IC, Yoon UH, Hahn JH, Koo BS, et al. (2005) The genome sequence of Xanthomonas oryzae pathovar oryzae KACC10331, the bacterial blight pathogen of rice. Nucleic Acids Res 33:577-586.

Llop P, Caruso P, Cubero J, Morente C and López MM (1999). A simple extraction procedure for efficient routine detection of pathogenic bacteria in plant material by polymerase chain reaction. J Microbiol Meth 1:23-31.

Monnet V (2003) Bacterial oligopeptide-binding proteins. Cell Mol Life Sci 60:2100-2114.

Moutran A, Balan A, Ferreira LC, Giorgetti A, Tramontano A and Ferreira RC (2007) Structural model and ligand interactions of the Xanthomonas axonopodis pv. citri oligopeptide-binding protein. Genet Mol Res 6:1169-1177.

Moutran A, Quaggio RB, Balan A, Ferreira LC and Ferreira RCC (2004) The oligopeptide permease (Opp) of the plant pathogen Xanthomonas axonopodis pv. citri. Curr Microbiol 48:354-359.

Nogales J, Muñoz S, Olivares J and Sanjuán J (2009) Genetic characterization of oligopeptide uptake systems in Sinorhizobium meliloti. FEMS Microbiol Lett 293:177-187.
Oshiro EE, Nepomuceno RSL, Faria JB, Ferreira LC and Ferreira RC (2006) Site-directed gene replacement of the phytopathogen Xanthomonas axonopodis pv. citri. J Microbiol Meth 65:171-179.

Parkinson N, Aritua V, Heeney J, Cowie C, Bew J and Stead D (2007) Phylogenetic analysis of Xanthomonas species by comparison of partial gyrase B gene sequences. Int J Syst Evol Microbiol 57:2881-2887.

Qian W, Jia Y, Ren SX, He YQ, Feng JX, Lu LF, Sun Q, Ying G, Tang DJ, Tang H, et al. (2005) Comparative and functional genomic analyses of the pathogenicity of phytopathogen Xanthomonas campestris pv. campestris. Genome Res 15:757-767.

Rudner DZ, LeDeaux JR, Ireton K and Grossman AD (1991) The spoOK locus of Bacillus subtilis is homologous to the oligopeptide permease locus and is required for sporulation and competence. J Bacteriol 173:1388-1398.

Salzberg SL, Sommer DD, Schatz MC, Phillippy AM and Lee NH (2008) Genome sequence and rapid evolution of the rice pathogen Xanthomonas oryzae pv. oryzae PXO99A. BMC Genomics 9:1-16.

Schaad NW, Postnikova E, Lacy GH, Sechler A, Agarkova I, Stromberg PE, Stromberg VK and Vidaver AK (2005) Reclassification of Xanthomonas campestris pv. citri (ex Hasse 1915) Dye 1978 forms A, B/C/D, and E as X. smithii subsp. citri (ex Hasse) sp. nov. nom. rev. comb. nov., X. fuscans subsp. aurantifolii (ex Gabriel 1989) sp. nov. nom. rev. comb. nov., and $X$. alfalfae subsp. citrumelo (ex Riker and Jones) Gabriel et al., 1989 sp. nov. nom. rev. comb. nov.; $X$. campestris pv malvacearum (ex smith 1901) Dye 1978 as $X$. smithii subsp. smithii nov. comb. nov. nom. nov.; $X$. campestris pv. alfalfae (ex Riker and Jones, 1935) dye 1978 as X. alfalfae subsp. alfalfae (ex Riker et al., 1935) sp. nov. nom. rev.; and "var. fuscans" of $X$. campestris $p v$. phaseoli (ex Smith, 1987) Dye 1978 as X. fuscans subsp. fuscans sp. nov. Syst Appl Microbiol 28:494-518.

Silva AC, Ferro JA, Reinach FC, Farah CS, Furlan LR, Quaggio RB, Monteiro-Vitorello CB, Van Sluys MA, Almeida NF and Alves LM (2002) Comparison of the genomes of two Xanthomonas pathogens with differing host specificies. Nature 417:493-563.

Thieme F, Koebnik R, Bekel T, Berger C, Boch J, Büttner D, Caldana C, Gaigalat L, Goesmann A, Kay S, et al. (2005) Insights into genome plasticity and pathogenicity of the plant pathogenic bacterium Xanthomonas campestris pv. vesicatoria revealed by the complete genome sequence. J Bacteriol 187:7254-7266.

Vauterin L, Hoste B, Kersters K and Swings J (1995) Reclassification of Xanthomonas. Int J Syst Evol Microbiol 45:472489.

Vorhölter FJ, Schneiker S, Goesmann A, Krause L, Bekel T, Kaiser O, Linke B, Patschkowski T, Rückert C, Schmid J, et al. (2008) The genome of Xanthomonas campestris $p v$. campestris $\mathrm{B} 100$ and its use for the reconstruction of metabolic pathways involved in xanthan biosynthesis. J Biotechnol 134:33-45.

Associate Editor: Carlos F.M. Menck

License information: This is an open-access article distributed under the terms of the Creative Commons Attribution License, which permits unrestricted use, distribution, and reproduction in any medium, provided the original work is properly cited. 